\title{
Optical properties of AIN thin films grown by plasma enhanced atomic layer deposition
}

Mustafa Alevli, Cagla Ozgit, Inci Donmez, and Necmi Biyikli

Citation: Journal of Vacuum Science \& Technology A: Vacuum, Surfaces, and Films 30, 021506 (2012); doi: 10.1116/1.3687937

View online: http://dx.doi.org/10.1116/1.3687937

View Table of Contents: http://avs.scitation.org/toc/jva/30/2

Published by the American Vacuum Society

\section{Articles you may be interested in}

Epitaxial growth of AIN films via plasma-assisted atomic layer epitaxy

Applied Physics Letters 103, 082110 (2013); 10.1063/1.4818792

Comparison of trimethylgallium and triethylgallium as "Ga" source materials for the growth of ultrathin GaN films on $\mathrm{Si}(100)$ substrates via hollow-cathode plasma-assisted atomic layer deposition

Journal of Vacuum Science \& Technology A: Vacuum, Surfaces, and Films 34, 01 A137 (2015);

$10.1116 / 1.4937725$

Initial growth, refractive index, and crystallinity of thermal and plasma-enhanced atomic layer deposition AIN films Journal of Vacuum Science \& Technology A: Vacuum, Surfaces, and Films 33, 01 A111 (2014);

$10.1116 / 1.4898434$

Room temperature atomic layer deposition of $\mathrm{TiO}_{2}$ on gold nanoparticles

Journal of Vacuum Science \& Technology A: Vacuum, Surfaces, and Films 35, $01 B 121$ (2016);

$10.1116 / 1.4971398$

Current transport mechanisms in plasma-enhanced atomic layer deposited AIN thin films

Journal of Applied Physics 117, 155101 (2015); 10.1063/1.4917567

Structural and chemical analysis of annealed plasma-enhanced atomic layer deposition aluminum nitride films Journal of Vacuum Science \& Technology A: Vacuum, Surfaces, and Films 34, 041506 (2016);

$10.1116 / 1.4953029$

Contact Hiden Analytical for further details: W www.HidenAnalytical.com E info@hiden.co.uk CLICK TO VIEW our product catalogue

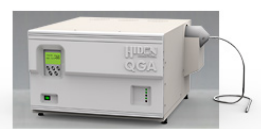

Gas Analysis

dynamic measurement of reaction gas streams catalysis and thermal analysis molecular beam studies , dissolved species probes 'sssolved spectesprobes

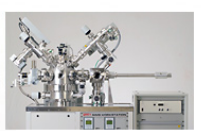

Surface Science

UHVTPD

end point detection in ion beam etch elemental imaging - surface mapping

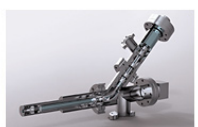

Plasma Diagnostics

, plasma source characterization etch and deposition process reaction kinetic studies analysis of neutral and radical species

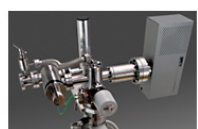

Vacuum Analysis partial pressure measurement and control of process gases reactive sputter process control vacuum diagnostics vacuum coating process monitoring 


\title{
Optical properties of AIN thin films grown by plasma enhanced atomic layer deposition
}

\author{
Mustafa Alevlia) \\ ${ }^{1}$ UNAM, Institute of Material Science and Nanotechnology, Bilkent University, 06800 Ankara, Turkey \\ and Physics Department, Faculty of Arts \& Sciences, Marmara University, 34722, Goztepe, Istanbul, Turkey \\ Cagla Ozgit, Inci Donmez, and Necmi Biyiklib) \\ ${ }^{2}$ UNAM, Institute of Material Science and Nanotechnology, Bilkent University, 06800 Ankara, Turkey
}

(Received 15 August 2011; accepted 23 January 2012; published 17 February 2012)

Crystalline aluminum nitride (AIN) films have been prepared by plasma enhanced atomic layer deposition within the temperature range of 100 and $500^{\circ} \mathrm{C}$. The AlN films were characterized by x-ray diffraction, spectroscopic ellipsometry, Fourier transform infrared spectroscopy, optical absorption, and photoluminescence. The authors establish a relationship between growth temperature and optical properties and in addition, the refractive indices of the AlN films were determined to be larger than 1.9 within the 300-1000 nm wavelength range. Infrared reflectance spectra confirmed the presence of $E_{1}(\mathrm{TO})$ and $A_{1}(\mathrm{LO})$ phonon modes at $\sim 660 \mathrm{~cm}^{-1}$ and $895 \mathrm{~cm}^{-1}$, respectively. Analysis of the absorption spectroscopy show an optical band edge between 5.78 and $5.84 \mathrm{eV}$ and the absorption and photoluminescence emission properties of the AlN layers revealed defect centers in the range of 250 and $300 \mathrm{~nm}$ at room temperature. (C) 2012 American Vacuum Society.

[DOI: $10.1116 / 1.3687937]$

\section{INTRODUCTION}

AlN films have promising physical and optical properties, including a high melting temperature $(2275 \mathrm{~K})$, high thermal conductivity at room temperature $\left(\sim 3.2 \mathrm{~W} \mathrm{~cm}^{-1} \mathrm{~K}^{-1}\right)$, high breakdown dielectric strength, high breakdown voltage, good chemical stability $(2500 \mathrm{~K})$, high electrical resistivity $\left(10^{13} \Omega \mathrm{cm}\right)$, and a wide band gap $(6.2 \mathrm{eV}){ }^{1,2}$ Furthermore, AlN exhibits the largest piezoelectric response in the IIInitride material family. ${ }^{3}$ Owing to the aforementioned material properties, AlN is suitable for applications in UV-visible detectors and emitters, optoelectronic displays, surface acoustic wave devices, high temperature devices, and dielectric passivation layers. ${ }^{4}$ In addition, its ability to form heterostructures with other III-nitrides makes AIN a suitable candidate for the fabrication of $\mathrm{Al}_{x} \mathrm{Ga}_{y} \mathrm{In}_{1-x-y} \mathrm{~N}^{4}$ based high-performance electronic and optoelectronic devices.

AlN thin films have been deposited using numerous growth techniques under different growth conditions and parameters (growth temperature, pressure, precursors and gases, etc.). While high-temperature (typically above $1100^{\circ} \mathrm{C}$ ) grown epitaxial AlN films are widely used in active electronic and optoelectronic device layers, polycrystalline and amorphous AlN films grown at CMOS-compatible temperatures (lower than $300^{\circ} \mathrm{C}$ ) find potential use as dielectric passivation layers for microelectronic devices. ${ }^{5}$ Atomic layer deposition (ALD) is a distinguished and alternative chemical vapor deposition technique to prepare conformal thin film coatings at low temperatures (typically below $300^{\circ} \mathrm{C}$ ). ${ }^{1}$ The most important feature of an ALD process is the selflimiting growth behavior due to the self-limiting surface reactions occurring for both precursors in each half-cycle.

\footnotetext{
a)Electronic mail: mustafaalevli@marmara.edu.tr

b)Electronic mail: biyikli@unam.bilkent.edu.tr
}

The temperature window in which saturation for both precursors are satisfied along with constant growth rate per cycle, is denoted as the ALD window. Recently, we demonstrated the self-limiting growth of AlN thin films at low temperatures by PEALD where trimethylaluminum (TMA) and $\mathrm{NH}_{3}$ precursors were introduced to the substrate alternately. Following the establishment of the self-limiting window, AlN films were deposited at various temperatures keeping the purging time, TMA pulse time, $\mathrm{NH}_{3}$ flow rate, and $\mathrm{NH}_{3}$ exposure time the same. ${ }^{6}$

In this work we explore the influence of the growth temperatures on the optical properties of AlN films grown by plasma-enhanced ALD. Although PEALD-grown AlN films formed at different substrate temperatures $\left(100-500^{\circ} \mathrm{C}\right)$ have been studied by several groups, ${ }^{7-9}$ the correlation between substrate temperature and optical material properties is not well understood at present. When AIN was deposited in the self-limiting growth window (ALD window), the growth rate per cycle remained constant at $0.84 \AA$ per cycle for temperatures up to $200{ }^{\circ} \mathrm{C}$, and then increased with temperature. ${ }^{10}$ Temperature dependency of the deposition rate observed at higher temperatures $\left(>200^{\circ} \mathrm{C}\right)$ can be attributed to TMA decomposition (complete TMA decomposition occurs above $\left.300{ }^{\circ} \mathrm{C}\right) .{ }^{11}$

\section{EXPERIMENT}

AlN films were deposited on $\mathrm{Si}(100), \mathrm{Si}(111)$, quartz, and sapphire substrates using a Cambridge Nanotech Fiji F200 ALD reactor operating under a base pressure of 0.2 Torr and using Ar as the carrier and purging gas. Trimethylaluminum (TMA) and remote rf-plasma enhanced decomposition of ammonia $\left(\mathrm{NH}_{3}\right)$ has been utilized as $\mathrm{MO}$ (metalorganic) and nitrogen precursors, respectively. For all growth experiments, the $\mathrm{NH}_{3}$ gas flow rate was kept at $50 \mathrm{sccm}$ and the 
TMA pulse duration was kept at $0.1 \mathrm{~s}$ with a purge time of $10 \mathrm{~s}$ while the plasma power was maintained at $300 \mathrm{~W}$. The processing parameters are summarized in Table I. To investigate the effect of the growth temperature on the optical properties of AlN films, $\sim 100 \mathrm{~nm}$ thick AlN layers were deposited at $100,185,400$, and $500{ }^{\circ} \mathrm{C}$.

The AlN layers deposited on $\mathrm{Si}(100)$ substrates were analyzed by spectroscopic ellipsometry, Fourier transform infrared spectroscopy (FTIR), and photoluminescence measurements, and AlN layers grown on quartz and sapphire substrates were investigated by optical transmission and IR reflection measurements. The silicon substrates were cleaned by the standard RCA process ${ }^{12}$ in order to remove any organic and inorganic surface contamination. Afterwards, the substrates were dipped in HF to remove the native oxide layer, nitrogen-dried, and immediately loaded via a load lock chamber into the reactor.

The crystalline structure of the grown AlN films were studied by grazing incidence $\mathrm{x}$ ray diffraction (GIXRD), using a grazing angle of $0.3^{\circ}$. The film thickness and refractive index were analyzed using a J.A.Woollam spectroscopic ellipsometer with a xenon light source. The ellipsometric data $(\Psi(65,70,75), \Delta)$ within the spectral range of 300-1000 nm together with the Cauchy model for a multilayer stack were used to estimate the thickness of the AlN films. The growth rate per cycle was calculated by dividing the film thickness by the total number of ALD cycles. Room temperature transmission measurements were performed with a UV-visible-near infrared spectrometer (Cary Varian 100 UV-VIS spectrometer), which consists of a built-in phase-sensitive detection and signal processing unit for the appropriate wavelength regions. Infrared measurements in reflection geometry were carried out using an FTIR spectrometer (Bruker Vertex 70) with a mirror optics microscope (hyperion microscope) and a liquid nitrogen cooled mercury cadmium telluride detector. Room-temperature FTIR spectra were taken over the frequency range of $400-7500 \mathrm{~cm}^{-1}$ $(25-1.33 \mu \mathrm{m})$ with a spectral resolution of $4 \mathrm{~cm}^{-1}$. All IR reflection spectra were taken under a normal incident light arrangement in order to minimize anisotropy effects. A gold mirror on glass was used as the reference sample for the normalization procedure. The photoluminescence (PL) measurements were carried out using a Cary eclipse flourescence spectrophotometer (VARIAN) employing a photomultiplier

TABle I. Process and sequence conditions for depositing PEALD AlN films.

\begin{tabular}{lc}
\hline \hline Sequence to deposit AlN & \\
\hline 1. TMA (carried by Ar $60 \mathrm{sccm})$ & $0.1 \mathrm{~s}$ \\
2. Ar $(200 \mathrm{sccm})$ & $10 \mathrm{~s}$ \\
3. Ar/ $/ \mathrm{NH}_{3}(200 \mathrm{sccm} / 50 \mathrm{sccm})$ & $40 \mathrm{~s}$ \\
4. Ar $(200 \mathrm{sccm})$ & $10 \mathrm{~s}$ \\
Process conditions & \\
Deposition temperature & $0.2 \mathrm{Torr}$ \\
Base pressure & $300 \mathrm{~W}$ \\
Plasma power & $\mathrm{Si}(100)$, quartz, sapphire \\
Substrate &
\end{tabular}

tube and a Xe arc discharge lamp as the excitation light source.

\section{RESULTS AND DISCUSSION}

\section{A. Film growth and structural properties}

Figure 1 depicts the dependence of the deposition rate on the substrate temperature and suggests that there are two different temperature regimes where different growth mechanisms control the growth. Growth rate per cycle (GPC) data suggests that below $200{ }^{\circ} \mathrm{C}$, the GPC remains almost constant at $0.84 \AA$ where the growth mechanism is controlled by selflimited surface reactions, i.e., incoming precursor molecules can only react with the species bound on the surface and gasphase reactions are eliminated. ${ }^{5}$ TMA and $\mathrm{NH}_{3}$ saturation was observed at $185^{\circ} \mathrm{C}$ in the "self-limiting ALD window" where the GPC is independent of the growth temperature and precursor dose. Furthermore, in our experiments the saturation of TMA was achieved at much shorter pulse times whereas longer metallic precursor pulse times were used in other ALD-grown AlN experiments. ${ }^{7,8}$ The deposition rate becomes temperature dependent for $T_{g} \geq 225^{\circ} \mathrm{C}$, which might be explained by the partial decomposition of TMA. TMA saturation curves gradually deviated from the self-limiting behavior at $\sim 250^{\circ} \mathrm{C}$. Further information regarding the behaviors of the TMA precursor and details of self-limiting growth of AlN can be found in the study by Ozgit et al. ${ }^{6}$

The GIXRD and transmission electron microscopy (TEM) of AIN films grown at $100,185,400$, and $500{ }^{\circ} \mathrm{C}$, indicate that the layers are composed of a highly polycrystalline hexagonal structure due to the observation of XRD Bragg reflexes of (100), (101), (002), (102), (110), and (103) diffraction planes. Similar GIXRD patterns were obtained for all AIN films deposited at different growth temperatures and AlN films retain their crystalline structure even at growth temperatures as low as $100^{\circ} \mathrm{C}$, as shown in Fig. 2. Analysis of HRTEM images show that the size of crystalline ordering becomes longer in length and the degree of crystallinity increases with higher growth temperatures. ${ }^{13}$

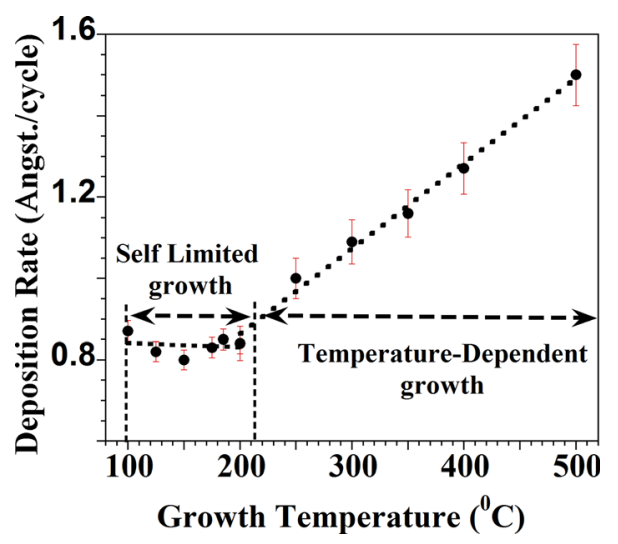

FIg. 1. (Color online) Deposition rate as a function of temperature. Deposition rate is constant at $0.84 \AA$ /cycle in the self-limiting ALD window. Above $200^{\circ} \mathrm{C}$, the deposition rate increases linearly with increasing growth temperatures due to the increased TMA decomposition. 


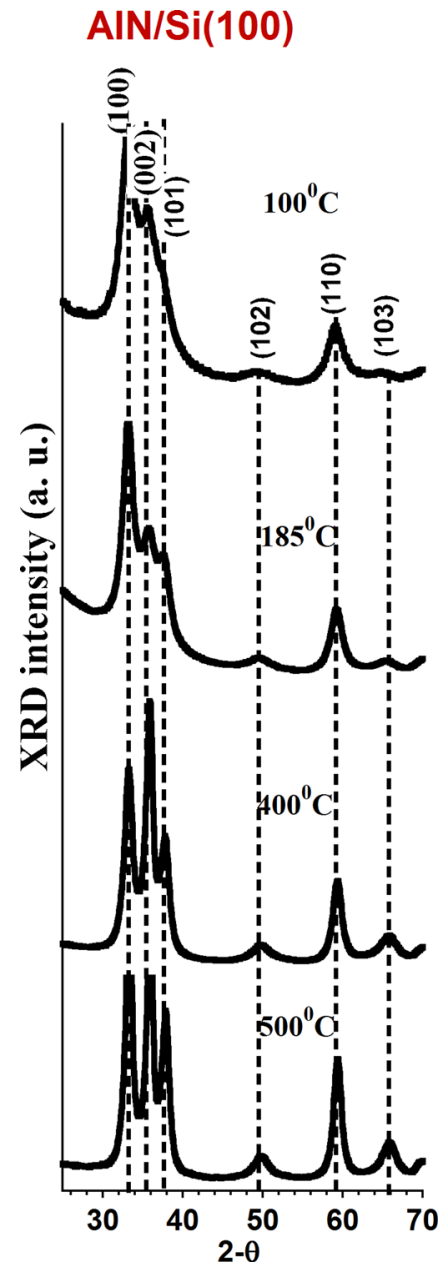

FIG. 2. (Color online) GIXRD patterns for AlN films at different growth temperatures on $\mathrm{Si}(100)$ with the growth parameters obtained in the selflimiting growth window.

\section{B. Optical properties}

The spectroscopic ellipsometry data were fitted using the Cauchy dispersion model. ${ }^{4}$ In the Cauchy model the refractive index, $n(\lambda)$, as a function of the wavelength is given by

$$
n(\lambda)=A+\frac{B}{\lambda^{2}}+\frac{C}{\lambda^{4}},
$$

where $A, B$, and $C$ are model parameters. Fitting was done by minimizing the mean square error, by using four fitting parameters. The change in the refractive index and extinction coefficient as a function of growth temperature is shown in Fig. 3(b). The refractive index value at $632 \mathrm{~nm}$ increased from 1.86 at $100^{\circ} \mathrm{C}$ to 1.94 at $185^{\circ} \mathrm{C}$ (within the selflimiting growth regime) and further increased to 2.05 for a growth temperature of $500^{\circ} \mathrm{C}$, indicating a densification of the AlN layers with increasing growth temperature. Refractive indices ranging from 1.9 to 2.1 have typically been reported for crystalline AlN films in the wavelength range of $300-1000 \mathrm{~nm}$. Single-crystal AIN films grown by MOCVD displayed refractive index values of $\sim 2.1$ at $\lambda=633 \mathrm{~nm} .^{8}$ The extinction coefficients are very small $(<0.0033)$ for AlN samples grown at 100,185 , and $400^{\circ} \mathrm{C}$, and are in the order of $10^{-6}$ for AlN layers grown at $500^{\circ} \mathrm{C}$. The extinction coefficients for AlN films grown at $100^{\circ} \mathrm{C}$ exhibit considerable deviation and are not congruent with extinction coefficients of films grown at higher temperatures. The variation of the refractive index with growth temperature can be modeled using a Bruggemann effective medium approximation. ${ }^{14}$ The fill fraction is as in the following:

$$
f_{\mathrm{AIN}} \frac{\varepsilon_{\mathrm{AlN}}-\varepsilon_{\mathrm{eff}}}{\varepsilon_{\mathrm{AIN}}+2 \varepsilon_{\mathrm{eff}}}+\left(1-f_{\mathrm{AIN}}\right) \frac{\varepsilon_{\mathrm{air}}-\varepsilon_{\mathrm{eff}}}{\varepsilon_{\mathrm{air}}+2 \varepsilon_{\mathrm{eff}}}=0,
$$

where $\varepsilon_{\mathrm{AIN}}, \varepsilon_{\mathrm{air}}=1$, and $\varepsilon_{\mathrm{eff}}$ correspond to the dielectric constants of ideal single-crystal AIN, air, and the experimentally achieved AIN film, respectively, and $f_{\text {AlN }}$ is the fill fraction of the AlN component. The fill fraction as a function of growth temperature is shown in Fig. 3(a) which confirms the reduction in optical film density, refractive index and local crystallinity with decreasing growth temperature.

To gain further insight about the film crystallinity and chemical bond structure, FTIR spectrometry measurements were carried out for the AlN films grown on $\mathrm{Si}(100)$ and double-side polished $c$-plane sapphire and are shown Figs. 4(a) and 4(b). For the AlN films grown on $\mathrm{Si}(100)$, the reflectance shows a pronounced broad Restrahlen band bracketed by transverse (TO) and longitudinal optical (LO) phonon energies. The reflectance spectra on $\mathrm{Si}(100)$ substrates evolve to show one maximum which is most closely associated with $E_{1}(\mathrm{TO})$ and $A_{1}(\mathrm{LO})$ phonons, respectively. ${ }^{15}$ The phonon band maximum position exhibits a slight blue shift with increasing temperature which indicates biaxial compressive strain in AlN films. ${ }^{16}$ A large peak centered at 694 and

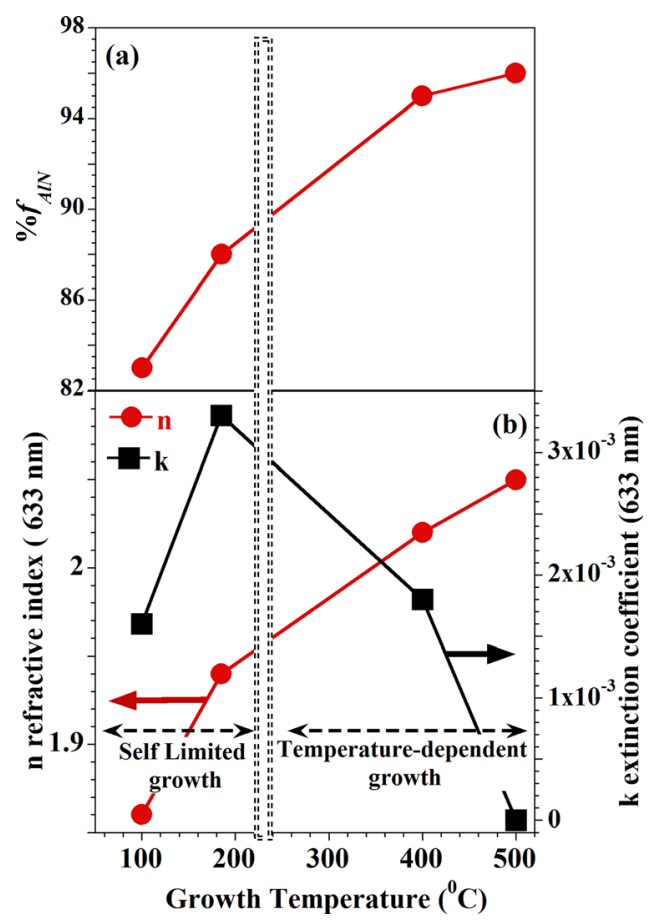

FIg. 3. (Color online) Change in the (a) fill fraction of AlN films, (b) refractive index and extinction coefficient of AlN layers as a function of growth temperature. 


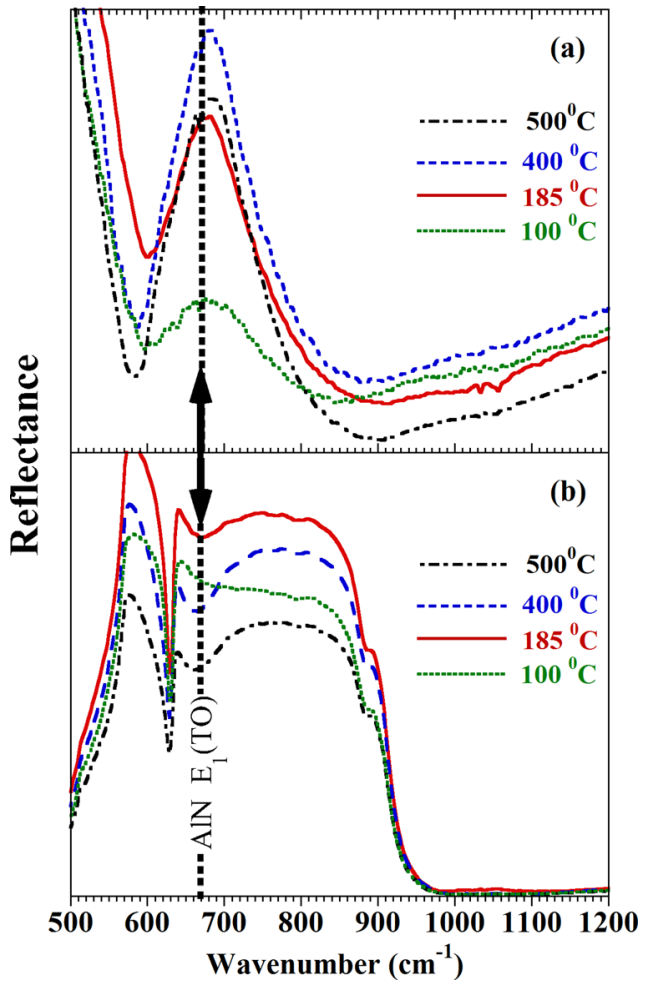

FIG. 4. (Color online) FTIR spectra of AIN films on (a) Si(100), (b) sapphire at different temperatures.

$681 \mathrm{~cm}^{-1}$ was observed for samples grown in the self-limiting growth window at 100 and $185^{\circ} \mathrm{C}$, respectively. On the other hand, the peak maximum shifted to $\sim 684 \mathrm{~cm}^{-1}$ for samples grown in the temperature-dependent growth regime at 400 and $500{ }^{\circ} \mathrm{C}$, respectively. The transfer matrix was used to calculate IR reflectance spectra from the multilayer structures (Air/AlN/sapphire). ${ }^{17}$ The phonon contribution arises from lattice vibrations under the propagating electric field of the incident light modeled using a Lorentz oscillator. The frequency dependent complex dielectric function is

$$
\varepsilon(\omega)=\varepsilon_{\infty}\left[1+\frac{\omega_{\mathrm{LO}}^{2}-\omega_{\mathrm{TO}}^{2}}{\omega_{\mathrm{TO}}^{2}-\omega^{2}-i \omega \Gamma}\right]
$$

where $\omega_{\mathrm{TO}}$ and $\omega_{\mathrm{LO}}$ are the transverse and longitudinal optical phonon frequencies, respectively, $\Gamma$ is the broadening constant of the $E_{1}(\mathrm{TO})$ phonon, $\omega$ is the incident light frequency and $\varepsilon_{\infty}$ is the high frequency dielectric constant. Free carrier effects are neglected since AIN layers are nominally undoped. The optical constants, $\varepsilon_{\infty}, \omega_{\mathrm{TO}}, \omega_{\mathrm{TO}}$, and $\Gamma$, for AlN layers were extracted by fitting the experimental IR reflectance data and are listed in Table II. The experimental and modeled IR reflectance spectra for AlN films grown at $400{ }^{\circ} \mathrm{C}$ are shown in Fig. 5. The high frequency constant did not vary significantly but remained around 4.84 . The frequency of the $E_{1}(\mathrm{TO})$ phonon was found to be at $667 \mathrm{~cm}^{-1}$ for samples grown at $500^{\circ} \mathrm{C}$. However, the phonon positions shifted to 660 and $653 \mathrm{~cm}^{-1}$ for samples grown at 400 and $185^{\circ} \mathrm{C}$, respectively.

In literature, it was reported that crystalline AlN exhibits characteristic $E_{1}(\mathrm{TO})$ vibration modes at $\sim 665 \mathrm{~cm}^{-1}$ for thick
TABLE II. Parameters obtained from the best fits of IR spectra and sample information. Growth temperatures, the high frequency dielectric constant $\left(\varepsilon_{\infty}\right), E_{1}(\mathrm{TO})$, and $A_{1}(\mathrm{LO})$ mode frequencies, and the damping constant of $\mathrm{E}_{1}(\mathrm{TO})(\Gamma)$.

\begin{tabular}{lcccc}
\hline \hline Growth temperatures & $\varepsilon_{\infty}$ & $\begin{array}{c}\omega_{\mathrm{LO}} \\
\left(\mathrm{cm}^{-1}\right)\end{array}$ & $\begin{array}{c}\omega_{\mathrm{TO}} \\
\left(\mathrm{cm}^{-1}\right)\end{array}$ & $\begin{array}{c}\Gamma \\
\left(\mathrm{cm}^{-1}\right)\end{array}$ \\
\hline $185^{\circ} \mathrm{C}$ & 4 & 895 & 653 & 125 \\
$400^{\circ} \mathrm{C}$ & 4.84 & 897 & 660 & 50 \\
$500^{\circ} \mathrm{C}$ & 4.84 & 895 & 667 & 38 \\
\hline \hline
\end{tabular}

polycrystalline AlN layers and at $675-680 \mathrm{~cm}^{-1}$ for highly textured thin films. ${ }^{18}$ The characteristic $E_{1}(\mathrm{TO})$ phonon mode positions that we observed for all AlN films in the range of $650-670 \mathrm{~cm}^{-1}$ confirms that all AlN films are polycrystalline. For the AlN layer grown at $100^{\circ} \mathrm{C}$, only a broad peak instead of a minima is observed, and the $E_{1}(\mathrm{TO})$ phonon position could not be extracted. No additional information was obtained in the high wavenumber range above $1200 \mathrm{~cm}^{-1}$. FTIR spectra for both AlN films on various substrates show no evidence of an $A_{1}(\mathrm{LO})$ phonon of AlN at $890 \mathrm{~cm}^{-1}$.

The optical transmittances of the AlN films grown on a quartz substrate are shown in Fig. 6(a) for the 175-800 nm wavelength range. The onset of the transmission for samples grown within the self-limiting growth regime starts at $\sim 188 \mathrm{~nm}$ whereas the onset of the transparency for samples grown in the temperature-dependent growth regime redshifted to $\sim 197 \mathrm{~nm}$. Absorption bands centered below the optical band gap observed at $\sim 250 \mathrm{~nm}$ for both AlN films grown in the self-limiting growth regime were associated with the vacancy and impurity related defects $\mathrm{O}_{\mathrm{N}}$ and $\mathrm{V}_{\mathrm{Al}} \cdot{ }^{19}$ The absorption band for AlN films grown in the temperature-dependent growth regime is observed in between 280 and $320 \mathrm{~nm}$ and is attributed to the oxygen related impurities. ${ }^{20}$ The spectral absorption was determined as shown in Fig. 6(b), where the squared absorption coefficient, $\alpha^{2}$, is plotted as a function of wavelength in order to determine the optical band edge energy for deposited AlN films. The optical band edge can be determined by extrapolating the line tangential to the wavelength axis in the $\alpha^{2} d^{-2}$ vs $\lambda$ plot. Here we have expressed the absorption as $\alpha^{2} d^{-2}$ since AlN is known as a direct bandgap material and electronic transitions are allowed between parabolic bands. AlN samples grown in the temperaturedependent growth region have the same optical band edge observed at $5.78 \mathrm{eV}$, while AlN samples grown at 185 and $100{ }^{\circ} \mathrm{C}$ show an optical band edge observed at 5.84 and $5.82 \mathrm{eV}$, respectively. Although there is a shift in the absorption band edge of AlN films grown in the self-limited regime, no significant change in the absorption band edge of AIN films grown in the temperature-dependent regime were observed as shown in Fig. 6(b).

Room temperature PL spectroscopy measurements were carried out to assess additional information about the optical quality and influence of the crystal defects and impurities on the optical properties of the AIN films. A summary of the PL results for the analyzed samples is presented in Fig. 7. Due to the technical limitation for our PL setup, the maximum 


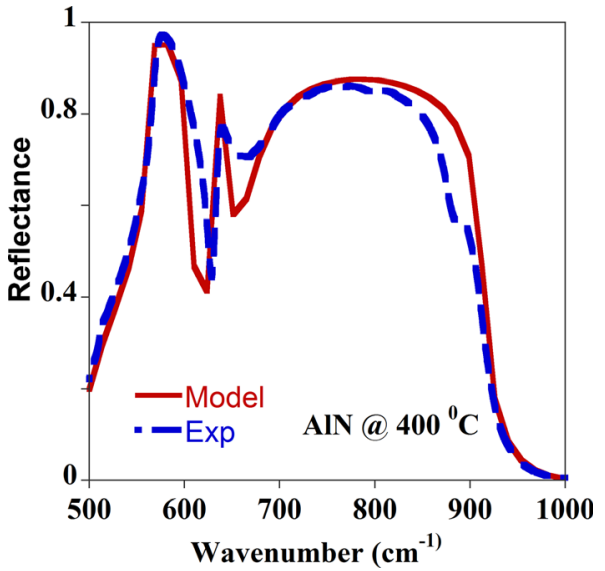

FIG. 5. (Color online) Experimental reflectance spectra (dotted lines) of AlN layer on sapphires substrate and the best fit using Eq. (3) (solid lines). AlN films grown at $400^{\circ} \mathrm{C}$

excitation energy was $5.84 \mathrm{eV}(\sim 210 \mathrm{~nm})$ and no feature for band-to-band transitions could be obtained. The luminescence above $5.64 \mathrm{eV}$ (below $220 \mathrm{~nm}$ ) was not evaluated because of the limited intensity output of the excitation source. For all AlN films, a broad PL emission peak in the range of $260 \mathrm{~nm}$ $(4.76 \mathrm{eV})-320 \mathrm{~nm}(3.87 \mathrm{eV})$ were observed. The PL peak
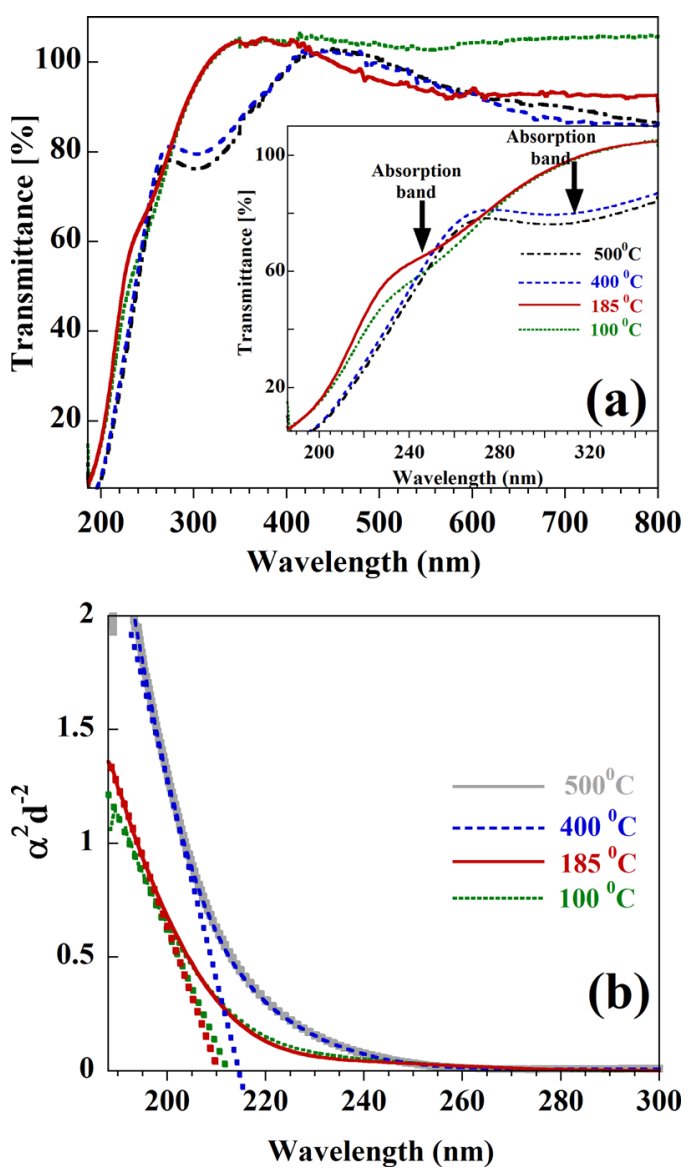

FIG. 6. (Color online) (a) Optical transmission spectra and (b) the square of the product of the experimental absorption as a function of wavelength for AlN films. The intersection of straight lines through the abscissa of the measured data yields the energy position of optical band edges.

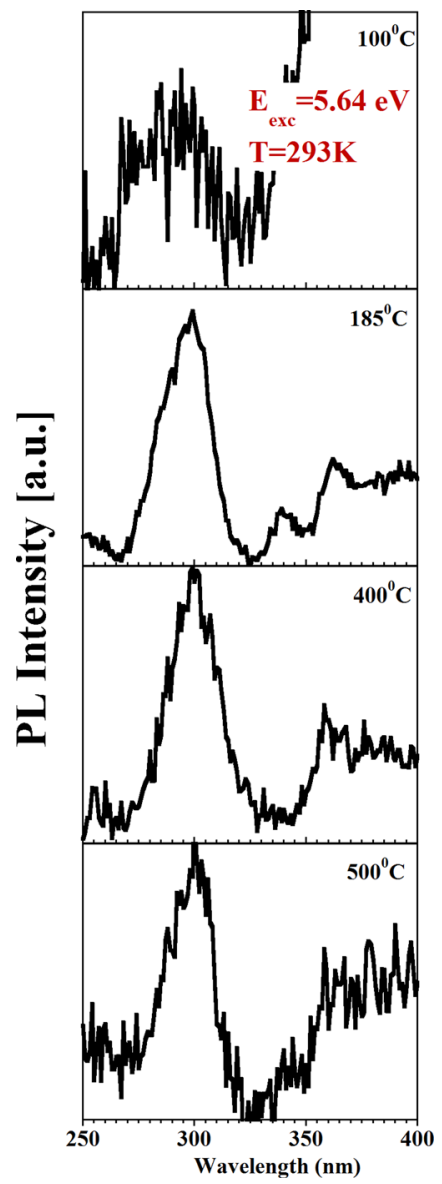

FIG. 7. (Color online) Photoluminescence (PL) as a function of AlN film growth temperature for all AIN films.

positions show a systematic shift towards higher energy except AlN sample grown at $100^{\circ} \mathrm{C}$. The PL structures of of AlN films are related to defect bands centered at $300.5 \mathrm{~nm}$ $\left(185^{\circ} \mathrm{C}\right), \quad 299.2 \mathrm{~nm} \quad\left(400^{\circ} \mathrm{C}\right), \quad 298.4 \mathrm{~nm} \quad\left(500^{\circ} \mathrm{C}\right), \quad$ and $286.7 \mathrm{~nm}\left(100^{\circ} \mathrm{C}\right)$ within the band gap of AlN. The origin of the defect centers is assumed to be related to oxygen complexes and related defects as previously reported. ${ }^{20,21}$ The PL peak around $\sim 4.1 \mathrm{eV}$ is detected in all samples and cannot be directly correlated to oxygen and hence, other impurities such as nitrogen vacancies, Al-N antisites, and related complexes might be the origin of these interior band gap transitions. Further investigation is needed to clarify this issue.

\section{CONCLUSIONS}

In summary, we have studied the optical properties of PEALD grown crystalline AlN films in two main growth regimes: self-limiting ALD window and temperaturedependent growth temperatures. Compared to previously published results, AlN films grown at very low temperatures showed significantly improved crystalline quality, a higher refractive index, better TO phonon characteristics, and a higher transmittance. The values of the refractive index obtained from spectroscopic ellipsometry reveal crystalline AlN films, which is in good agreement with the obtained $E_{1}(\mathrm{TO})$ phonon position and the volume fill fraction in the AlN layers. The 
refractive index and volume fill fraction data show a strong proportional dependence on growth temperature. FTIR results confirm the presence of strong $\mathrm{Al}-\mathrm{N}$ bonding in the films. The high frequency dielectric constant, $\varepsilon_{\infty}$, in temperature dependent grown AlN films is 4.84, which is close to the reported values for AlN films, ${ }^{22}$ however, $\varepsilon_{\infty}$ is found to be 4 for samples grown in the self-limiting growth window. The phonon position, $E_{1}(\mathrm{TO})$, shifts to lower wavenumbers with increasing temperature. The AlN films exhibit an excellent optical transmittance of $95 \%$ for visible light, making PEALD grown AlN films promising for optical applications. The pronounced midgap emission between 3.87 and $4.17 \mathrm{eV}$ (at RT) has been identified for AIN films and the PL maximum of AlN films were found to be blue-shifted with increasing growth temperature.

\section{ACKNOWLEDGMENTS}

This work was performed at UNAM supported by the State Planning Organization (DPT) of Turkey through the National Nanotechnology Research Center Project. N.B. acknowledges support from Marie Curie International Reintegration Grant (Grant No. PIRG05-GA-2009-249196). M.A. gratefully acknowledges the financial support from TUBITAK (Project No. 232.01-660/4835).

${ }^{1}$ Y. Lee and S.-Wang, Thin Solid Films 446, 227 (2004).

${ }^{2}$ E. F. McCullen, J. S. Thakur, Y. V. Danylyuk, G. W. Auner, and L. W. Rosenberger, J. Appl. Phys. 103, 063504 (2008).
${ }^{3}$ M. V. Pellegrini and I. Pereyra, Phys. Status Solidi C 7, 840 (2010).

${ }^{4}$ J. Khoshman and M. E. Kordesch, J. Non-Cryst. Solids 351, 3334 (2005).

${ }^{5}$ D. Riihela, M. Ritala, R. Matero, M. Leskela, J. Jokinen, and P. Haussalo, Chem. Vap. Deposition 2, 277 (1996).

${ }^{6}$ C. Ozgit, I. Donmez, M. Alevli, and N. Biyikli, Thin Solid Films 520, 2750 (2012).

${ }^{7}$ K. Kim, N. Kwak, and S. Lee, Electron Mater. Lett. 5, 83 (2009).

${ }^{8}$ M. Bosund, T. Sajavaara, M. Laitinen, T. Huhtio, M. Putkonen, V.M. Airaksinen, and H. Lipsanen, Appl. Surf. Sci. 257, 7827 (2011).

${ }^{9}$ X. Liu, S. Ramanathan, E. Lee, and T. E. Seidel, MRS Symp. Proc. 811D, D.19 (2004).

${ }^{10}$ H. Kim, J. Vac. Sci. Technol. A 21, 2231 (2003).

${ }^{11}$ D. Riihela, M. Ritala, R. Matero, M. Leskela, J. Jokinen, and P. Haussalo, Chem. Vap. Deposition 2, 277 (1996); R. L. Puurunen, M. Lindblad, A. Root, and A. O. Krause, Phys. Chem. Chem. Phys. 3, 1093 (2001).

${ }^{12}$ W. Kern, J. Electrochem.Soc. 137, 1887 (1990).

${ }^{13}$ M. Alevli, C. Ozgit, I. Donmez, and N. Biyikli, Phys. Status Solidi A 209, 266 (2012).

${ }^{14}$ D. A. G. Bruggeman, Ann. Phys. 24, 636 (1935).

${ }^{15}$ T. Prokofyeva, M. Seon, J. Vanbuskirk, M. Holtz, S. A. Nikishin, N. N. Faleev, H. Temkin, and S. Zollner, Phys. Rev. B 63, 125313 (2001).

${ }^{16}$ V. Darakchieva, P. P. Paskov, T. Paskova, J. Birch, S. Tungasmita, and B. Monemar, Appl. Phys. Lett. 80, 2302 (2002).

${ }^{17}$ M. Alevli, G. Durkaya, W. Fenwick, A. Weerasekara, V. Woods, I.T. Ferguson, A.G.U. Perera, and N. Dietz, Appl. Phys. Lett. 89, 112119 (2006).

${ }^{18}$ R. Y. Krupitskaya and G. W. Auner, J. Appl. Phys. 84, 2861 (1998).

${ }^{19}$ N. Nepal, M. L. Nakarni, J. Y. Lin, and H. X. Jiang, Appl. Phys. Lett. 89, 092107 (2006).

${ }^{20}$ M. Strassburg, J. Senawiratne, N. Dietz, U. Haboeck, A. Hoffmoann, V. Noveski, R. Dalmau, R. Schlesser, and Z. Sitar, J. Appl. Phys. 96, 5870 (2004).

${ }^{21}$ Y. C. Lan, X. L. Chen, Y. G. Cao, Y. P. Xu, L. D. Xun, T. Xu, and J. K. Liang, J. Cryst. Growth 207, 247 (1999).

${ }^{22}$ M. F. MacMillan, R. P. Devaty, and W. J. Choyke, Appl. Phys. Lett. 62, 770 (1993). 